\title{
O dilúvio universal e a América: relações entre as cosmovisões indígena e cristã no Códice Telleriano Remensis
}

\author{
Gláucia Cristiani Montoro[1]
}

\begin{abstract}
Resumo
Este artigo analisa os textos do Códice Telleriano Remensis, escritos por missionários dominicanos na Nova Espanha do século XVI, nos quais aparecem associações entre aspectos do cristianismo e mitos e práticas indígenas, como a referência a um dilúvio, demonstrando a preocupação dos frades em encontrar um lugar para os povos nativos da América na cosmovisão europeia cristã.

Palavras-chave: Nova Espanha; Códice Telleriano Remensis; missionários.
\end{abstract}

El diluvio universal y América: relaciones entre las cosmovisiones indígena y cristiana en el Códice Telleriano Remensis

\section{Resumen}

Este artículo analiza los textos del Códice Telleriano Remensis, escritos por misioneros dominicanos en la Nueva España del siglo XVI. En ellos pueden encontrarse asociaciones entre aspectos del cristianismo y mitos y prácticas indígenas, como las referencias a un diluvio, lo que demuestra la preocupación de los frailes por encontrar lugar a los pueblos indígenas de América en la cosmovisión europea cristiana.

Palabras clave: Nueva España; Códice Telleriano Remensis; misioneros.

The universal flood and America: Relations between indigenous and Christian worldviews at the Telleriano-Remensis Codex

\begin{abstract}
This paper analyzes the Telleriano-Remensis Codex texts written by Dominican missionaries in the $16^{\text {th }}$ century, in New Spain. Within these comments, many references can be found connecting aspects of Christianity to myths and practices from the indigenous population. References are made to a flood, pointing out the friars' concern to find a place for the American native people into the European Christian worldview.
\end{abstract}

Keywords: New Spain; Telleriano-Remensis Codex; missionaries.

Le déluge universel et l'Amérique: des rapports entre le paradigme indigène et celui chrétien dans le Codex Telleriano Remensis

Résumé

Cet article analyse les textes du Codex Telleriano Remensis, écrits par des missionaires dominicains au XVlème siècle en Nouvelle Espagne, dans lesquels il y a des associations entre certains aspects du christianisme et les mythes et pratiques indigènes, y incluse la mention d'un déluge, montrant le soin des frères vers l'ínsertion des peuples natifs de l'Amérique dans le paradigme Euro-Chrétien.

Mots-clés: Nouvelle Espagne; Codex Telleriano Remensis; missionnaires. 
$\mathrm{O}$ s códices ${ }^{1}$ pictográficos produzidos por diversos grupos indígenas da região mesoamericana estiveram entre os principais alvos de destruições empreendidas pelos missionários cristãos no início do período colonial no Novo Mundo. Por isso, foram poucos os exemplares pré-hispânicos que sobreviveram. Paradoxalmente, a maioria dos códices atualmente existente foi confeccionada durante o período colonial, muitos deles sob o patrocínio de ordens missionárias, especialmente os que possuíam conteúdos religiosos.

O Códice Telleriano Remensis data de meados do século XVI, um período em que as dificuldades linguísticas iniciais já tinham sido superadas, e entre os frades ${ }^{2}$ ampliava-se o interesse por diversos aspectos da cultura indígena. Mas, como explicar o empenho desses frades na compilação de pictografias e busca e registro de informações acerca de assuntos que os missionários dos primeiros anos de colonização tanto se empenharam em destruir?

Desde a década de 1520, mas principalmente a partir da segunda metade do século XVI, os missionários que atuavam na Nova Espanha mostraram especial curiosidade por alguns aspectos das culturas indígenas, principalmente pelos calendários, pelos deuses e pelas festividades relacionadas a eles. Apesar das destruições indiscriminadas de manuscritos, os religiosos perceberam a importância da compreensão das tradições indígenas para que pudessem realizar uma evangelização eficiente e combater a idolatria. Um grande esforço foi colocado na correlação entre os calendários indígenas e o calendário cristão, pois, desse modo, poderiam ser identificadas, no calendário europeu, as datas mais significativas da vida religiosa indígena durante o período pré-hispânico. Muitos dos missionários que compilaram pictografias nesse período ou escreveram livros com informação religiosa indígena, considerada idolátrica, justificam seus atos baseados na premissa de que a falta de conhecimento das tradições nativas prejudicava a fiscalização da Igreja. Alguns deles afirmam que os ameríndios praticavam atos idolátricos diante dos olhos dos missionários sem que esses se dessem conta. Sahagún, por exemplo, que pertencia à ordem franciscana, explicou o seguinte:

Elmédico no puede acertadamente aplicar las medicinas al enfermo sin que primero conozca de qué humor, o de que causa sea doctor en el conocimiento de las medicinas y en el de las enfermedades para aplicar conveniblemente a cada enfermedad la medicina contraria, y porque los predicadores y confesores médicos son de las animas, para curar las enfermedades espirituales conviene que tengan experiencia de las medicinas y de las enfermedades espirituales [...] conviene mucho que sepan lo necesario para ejercitar sus oficios; ni conviene se descuiden los ministros de esta conversión, como decir que entre esta gente no hay más pecados que borrachera, hurto y carnalidad, porque otros muchos pecados hay entre ellos muy más graves y que tienen gran necesidad de remedio: los pecados de la idolatría y ritos idolátricos, y supersticiones idolátricas y agüeros, y abusiones y ceremonias idolátricas, no son aún perdidos del todo.

\footnotetext{
'O termo códice vem da palavra em latim codex, usada originalmente para nomear pequenas tábuas enceradas utilizadas pelos romanos para escrever. O termo foi adicionado como um rótulo ou prefixo para intitular uma série de manuscritos no século XIX. Foi incluído também nos textos de origem mesoamericana. ${ }^{2} \mathrm{No}$ início do período colonial, a Coroa espanhola preferiu que os religiosos encarregados da evangelização dos indígenas na Nova Espanha pertencessem às ordens mendicantes e, por isso, frades de diversas ordens atuaram na região. No século XVI, as que mais se destacaram na coleta de informações sobre as culturas nativas foram a franciscana e a dominicana, especialmente a primeira.
} 
Para predicar contra estas cosas, y aun para saber si las hay, menester es de saber cómo las usaban en tiempo de su idolatría, que por falta de no saber esto en nuestra presencia hacen muchas cosas idolátricas sin que lo entendamos [... $]^{3}$

No final do século XVI e na primeira metade do XVII, a busca por vestígios idolátricos tornou-se quase uma obsessão entre os religiosos (tanto regulares como seculares), apesar da circulação mais cuidadosa de manuscritos devido às censuras, relativas aos textos que continham informações sobre os costumes e as práticas indígenas empreendidas por Filipe II, especialmente a partir da década de $1570 .{ }^{4}$ Jacinto de la Serna, por exemplo, um clérigo do século XVII, fez um alerta aos evangelizadores em seu "Manual de Ministros de Índios":

Pues después de tanta luz, de tanta predicación, y trabajos, auiendo de estar llenos de luz, están metidos en tan obscuras tinieblas, y auiendo de resplandecer con obras de verdaderos cristianos, se descubren en ellos obras de verdaderos idolatras [...]; pues brotan en ellos las tinieblas de la idolatría, que tienen y han tenido encubierta, que esta nunca la han dejado, sino que desde, que á los principios se les predicó la fe, la tienen, y obran con tanta astucia, que aunque idolatren delante de los españoles, y aun en presencia de sus mismos ministros, no se les conoce la idolatría [... $]^{5}$

Portanto, tudo indica que o Códice Telleriano Remensis foi realizado para ser uma fonte de informações sobre as culturas nativas. Trata-se de um manuscrito proveniente da região central do México, composto por pictografias (um sistema de notação pictográfico característico do México Central) e textos em caracteres latinos (a maioria em castelhano, mas também possuem algumas palavras em náhuatl), ${ }^{6}$ tendo sido realizado em papel europeu e em formato de códice ${ }^{7}$. Logo, trata-se de uma fonte híbrida, que mescla convenções de distintos sistemas de escrita e formatos de livros, assim como concepções visuais muito diferentes. É dividido em três partes ou seções: as duas primeiras de caráter calendárico-religioso e a última, de fundo histórico. A primeira mostra o Xiuhpohualli, ou ciclo calendárico anual de 365 dias (dividido em 18 festas, ou 18 "meses" de 20 dias cada, mais uma página representando os cinco dias adicionais, chamados nemontemi); a segunda é um Tonalpohualli ou calendário ritual (de 260 dias, dividido em grupos de 13, conhecidos como Trecenas); ${ }^{8}$ e a terceira aborda conteúdos históricos (desde as migrações típicas dos povos

\footnotetext{
33ernardino de Sahagún, Historia general de las cosas de Nueva España, 10. ed., México, Editorial Porrúa, 1999 , p. 17. ${ }^{4}$ Um documento muito conhecido sobre tal censura é uma Cédula Real de Filipe II, de 22 de abril de 1577 , na qual o rei ordenou que os manuscritos produzidos pelo franciscano Bernardino de Sahagún fossem recolhidos (apud Luiz Estevam de Oliveira Fernandes, Histórias de um silêncio: as leituras de história eclesiástica indiana de Frei Jerônimo de Mendieta, Dissertação de Mestrado em História, Universidade Estadual de Campinas, Campinas, 2004, p. 61-62).

5Jacinto de la Serna, "Manual de Ministros de Índios", In: El alma encantada. Anales del Museo Nacional de México, México, Instituto Nacional Indigenista/Fondo de Cultura Económica, 1987, p. 279.

${ }^{6} \mathrm{O}$ náhuatl era a língua falada pelas elites e por uma grande parte da população da área central do território atual do México antes da invasão europeia. Era o idioma dos mexicas (mais conhecidos como astecas). Durante o período colonial, foi transliterado em caracteres latinos com o uso da ortografia e da fonética do castelhano.

${ }^{7}$ Formato de códice é um tipo específico de formato de livro composto por fólios (de papel, pergaminho ou papiro) unidos entre si por sua margem interna.

${ }^{8}$ Preferimos usar o nome dado pelos espanhóis a essas divisões, Trecenas.
} 
nahuas ${ }^{9}$ passando por sua história dinástica, até a colonial), as quais preferimos subdividir em duas partes: Migração e Anais Históricos.

As pictografias foram os objetos de pesquisa de nosso doutorado, ${ }^{10}$ no qual realizamos um estudo codicológico e uma análise formal e estilística dos escribas/pintores ou tlacuilos. ${ }^{11}$ No referido estudo, foi possível reconstruir a história de confecção do manuscrito e observar que os tlacuilos, além de adotarem uma série de convenções pertencentes à tradição ocidental, demonstram características de distintas tradições regionais indígenas (dos Vales do México e de Puebla), uma vez que, no códice, aparecem diferentes estilos, de acordo com o pintor que realizou cada uma de suas partes. Notamos também que cada um dos sete tlacuilos identificados realizou adaptações particulares dos conteúdos tradicionais - de seus grupos ou de grupos vizinhos - para satisfazer às exigências dos patronos ocidentais, por um lado, e do suporte europeu, por outro, ou seja, o papel fabricado em Gênova e organizado em formato de códice, ainda desconhecido no mundo pré-colombiano.

O fato de as pictografias do Telleriano Remensis estarem acompanhadas por textos em espanhol, de o documento ter sido realizado com papel confeccionado na Europa e em formato de códice (livro europeu), de a direção de leitura coincidir com aquela utilizada nos textos ocidentais, dentre outros motivos, revelam que tal manuscrito foi patrocinado e compilado por esses colonizadores. O conteúdo dos textos em caracteres latinos sugere ainda que foi realizado especificamente por missionários. Há anotações em todas as seções do códice, as quais, possivelmente, foram inseridas para explicar o conteúdo das imagens, apesar de existirem comentários que não se relacionam diretamente com elas, especialmente no final do manuscrito. Todos os textos são fruto do esforço de vários anotadores e foram inseridos paulatinamente em diferentes períodos da história de confecção do documento.

De acordo com as análises realizadas em nosso estágio de pós-doutorado, ${ }^{12}$ dez indivíduos participaram de tal processo, ${ }^{13}$ os quais organizamos por números, de um a dez, atribuídos de acordo com a importância de seus textos e sua ordem de aparição no manuscrito. Assim, os cinco primeiros foram os anotadores principais, ou seja, aqueles que realizaram as redações mais importantes e extensas, enquanto os cinco últimos somente incluíram pequenas frases ou escreveram algumas palavras no idioma nahuatl. O Anotador 1 foi identificado como o frade dominicano Pedro de los Ríos, que trabalhou em todas as seções

\footnotetext{
${ }^{9}$ Referente àqueles que falavam o idioma náhuatl. A grafia foi adaptada ao português. ${ }^{10} \mathrm{Gláucia}$ Cristiani Montoro, Memórias fragmentadas: novos aportes à história de confecção e formação do Códice Telleriano Remensis. Estudo codicológico, Tese de Doutorado em História Cultural, Universidade Estadual de Campinas, Campinas, 2008.

"1"Tlacuilo o tlacuiloani: escritor, pintor" (Siméon Rémi, Diccionario de la lengua Náhuatl o mexicana, Madrid, Siglo Veintiuno, 1992, p. 581). Em náhuatl, o plural de tlacuilo é tlacuiloque, mas foi usado neste trabalho em sua forma adaptada ao espanhol e ao português, nos quais o plural é realizado adicionando-se o "s".

${ }^{12}$ Realizado na Universidade Federal Fluminense, com supervisão do Professor Dr. Ronaldo Vainfas e bolsa do Conselho Nacional de Desenvolvimento Científico e Tecnológico (CNPq).

${ }^{13} \mathrm{~A}$ análise anterior mais detalhada dos textos do Telleriano Remensis foi efetuada por Quiñones Keber, tendo ela encontrado seis autores (Eloise Quiñones Keber, Codex Telleriano-Remensis: ritual, divination and history in a pictorial Aztec manuscript, Austin, University of Texas Press, 1995, p. 125-127).
} 
do códice, normalmente como redator secundário, ${ }^{14}$ com exceção da primeira parte da seção histórica (Migração), na qual foi o único a realizar comentários. O Anotador 2 também trabalhou em mais de uma seção. Foi autor dos textos primários do Xiuhpohualli e de alguns secundários do Tonalpohualli. Aquele que denominamos Anotador 3 pode ser considerado o comentador primário do Tonalpohualli, pois seus textos foram os únicos planejados para estarem nessa seção, tendo sempre a mesma localização em cada uma das Trecenas. Também foi o anotador primário do início dos Anais Históricos, das páginas 29r a 39r do fac-similar. ${ }^{15} \mathrm{O}$ Anotador 4 é o segundo ${ }^{16}$ anotador primário dos Anais Históricos: das páginas 39v a 47v. Já o Anotador 5 introduziu comentários nas páginas $41 \mathrm{v}$, $48 \mathrm{r}$ e no final do manuscrito, páginas $49 \mathrm{v}$ e $50 \mathrm{r}$, nas quais realizou notas extensas em duas páginas que não possuem pictografias, somente textos seus e de Pedro de los Ríos (na página 50r). Acreditamos que também tenha adicionado algumas palavras em letra gótica no Tonalpohualli.

\section{Os mais importantes textos do Códice Telleriano \\ Remensis revelam conhecimentos acerca das culturas indigenas coletados por um grupo de frades que atuava na Nova Espanha}

O Anotador 6 foi o primeiro identificado dentre aqueles que realizaram pequenas contribuições. Acreditamos que tenha sido o autor dos nomes das festas em letra gótica do Xiuhpohualli e de um dos textos, também em gótico, da primeira página do Tonalpohualli. Já os Anotadores 7, 8 e 9 incluíram palavras ou pequenos textos no Tonalpohualli: o Anotador 7 foi o responsável pelos nomes dos signos calendáricos, dos Senhores da Noite ${ }^{17}$ e autor do segundo grupo de textos da página 8r; o Anotador 8 inseriu uma frase na página 12v; e o Anotador 9 fez pequenos comentários nas páginas 16v, 17r e 23v. Por fim, o Anotador 10 escreveu as letras góticas com os nomes dos soberanos de México Tenochtitlan nos Anais Históricos.

Esse grande número de autores e a inclusão paulatina dos textos tornaram as anotações do Telleriano Remensis extremamente heterogêneas. As quatro partes do códice (considerando a seção histórica dividida em duas partes -

\footnotetext{
${ }^{14}$ Dentre os anotadores, foi feita uma distinção entre primários e secundários em cada uma das seções. Os textos primários foram os primeiros a serem adicionados em cada uma das seções e são posicionados, normalmente, em locais planejados e padronizados, abaixo das pictografias. Os outros textos ou palavras, quer sejam a adição de novos dados, correções ou complementações, foram considerados secundários. ${ }^{15}$ Para a indicação de páginas do códice ao longo deste trabalho, utilizaremos a numeração do fac-similar publicado pela Universidade do Texas (Eloise Quiñones Keber, Codex Telleriano-Remensis: ritual, divination and history in a pictorial Aztec manuscript, Austin, University of Texas Press, 1995).

${ }^{16}$ Existem dois autores primários nos Anais. O primeiro (Anotador 3) comentou as páginas 29r a 39r e o segundo (Anotador 4), 39v a 47v.

${ }^{17}$ Os "Senhores da Noite" se tratam de nove deidades que presidem cada um dos dias do Tonalpohualli.
} 
Migração e Anais Históricos) revelam distintos padrões de anotação, mesmo se forem consideradas apenas as anotações primárias, pois os comentários tiveram que se adaptar ao conteúdo pictográfico, que apresenta uma disposição diferente ou está organizado de modo distinto em cada um dos conteúdos do manuscrito. Neste artigo, nossa atenção estará voltada para esses textos em caracteres latinos do Códice Telleriano Remensis, especificamente para aqueles contidos nos dois primeiros assuntos do manuscrito, de conteúdo calendárico-religioso, o Xiuhpohualli e o Tonalpohualli.

\section{Os anotadores dos conteúdos calendárico-religiosos}

O códice Telleriano Remensis encontra-se atualmente incompleto, faltandolhe fólios das três seções. Em todos os casos, o conteúdo pictográfico pode ser recomposto utilizando-se o Códice Vaticano A, pois as três seções do primeiro são idênticas às do segundo, que possui ainda alguns assuntos adicionais. O chamado Códice Vaticano A é também um manuscrito de meados do período colonial mexicano, composto por pictografias e textos em caracteres latinos, mas em língua italiana, diferentemente do Telleriano Remensis, cujas anotações mais extensas encontram-se em castelhano. Humboldt ${ }^{18}$ foi o primeiro autor a notar as semelhanças existentes entre os dois manuscritos, no início do século XIX, período também em que foram encontrados nos textos de ambos os códices evidências de sua relação com o frade dominicano Pedro de los Ríos. A conexão do Códice Vaticano A com tal frade já tinha sido determinada desde o século XVII, mas no século XIX foi possível conectar também o Códice Telleriano Remensis a ele. A relação é fundamentada principalmente pela análise de duas passagens, cada uma no texto de um dos manuscritos: em terceira pessoa no texto do Vaticano $A^{19}$ e em primeira no Telleriano Remensis. ${ }^{20}$ Essa evidência, associada à similaridade entre os dois manuscritos e à referência do nome de Ríos como o compilador do Códice Vaticano A, além de outras informações encontradas nos textos do Telleriano Remensis atribuídos a ele, ${ }^{21}$ mostra que o Telleriano pode ter sido compilado ou, no mínimo, passou pelas mãos desse frade, tendo sido ele, provavelmente, um de seus anotadores (nomeado neste trabalho como Anotador 1).

Devido à existência de documentos semelhantes produzidos sob os auspícios de ordens missionárias na Nova Espanha, ao custo que estaria agregado à

\footnotetext{
${ }^{18}$ Alexander Von Humboldt, Vues des cordillères et monumens des peuples indigènes de L'Amérique, Paris, F. Schoell, 1810, p. 279.

${ }^{19}$ Página 23r do fac-similar: Codex Vaticanus 3738. Facsímil del Codex Vatic. Lat. 3738 de la Biblioteca Apostólica Vaticana, Graz (Austria), Akademische Druck-u. Verlagsanst (ADEVA), 1996.

20Página 15r do fac-similar: Eloise Quiñones Keber, Codex Telleriano-Remensis: ritual, divination and history in a pictorial Aztec manuscript, Austin, University of Texas Press, 1995.

${ }^{21}$ Tais fatos coincidem com alguns dados coletados sobre sua vida nas Actas Capitulares de los Dominicos (Archivo Histórico - INAH, Cidade do México/Bancroft Collection, Berkeley), em que é manifesto que possuía conhecimento sobre a região de Oaxaca, e em um documento do Archivo General de Indias (Justicia 160 No 2. "Los indios y principales de la Nueva España con(tra) los prelados de ella sobre el pagar de los diezmos los dichos indios", 1559), o qual confirma sua passagem por diversas regiões da Nova Espanha, além de mostrar que falava pelo menos uma língua nativa, possivelmente o náhuatl.
} 
produção desse tipo de documento e ao grande número de mãos envolvidas na realização das anotações, dentre as quais podem ser identificados outros religiosos além de Ríos (cujos nomes são desconhecidos), acreditamos que esse manuscrito tenha pertencido à Ordem Dominicana. Pedro de los Ríos foi um de seus principais anotadores e, possivelmente, o compilador dos conteúdos. Sendo assim, os mais importantes textos do Códice Telleriano Remensis revelam conhecimentos acerca das culturas indígenas coletados por um grupo de frades que atuava na Nova Espanha no início do período colonial. Tais textos revelam a experiência pessoal desses frades durante o período em que estiveram em contato com diferentes grupos indígenas, especialmente nos locais onde havia unidades da ordem a que possivelmente pertenciam, a Ordem Dominicana.

Cada um dos dez anotadores do códice, principalmente os cinco principais, mostra uma forma particular de reunir informações no manuscrito. Nas duas seções que serão abordadas neste artigo, a primeira e a segunda, trabalharam oito dos dez anotadores discriminados. A primeira, do Xiuhpohualli, foi anotada por três indivíduos: o Anotador $2^{22}$ foi o comentador primário, enquanto o Anotador 1 e o Anotador 6 podem ser considerados os secundários. Os dois principais são o Anotador 1 e o Anotador 2, por terem realizado as notas mais importantes e extensas. Na segunda seção, do Tonalpohualli, trabalharam oito pessoas: o Anotador 3 foi o comentador primário, enquanto os Anotadores 1, 2, 5, 6, 7, 8 e 9 fizeram diversos tipos de inclusões. Os textos mais extensos pertencem aos Anotadores 1, 2 e 3, enquanto os Anotadores 5, $6,7,8$ e 9 somente fizeram pequenas contribuições ou acrescentaram alguns nomes em náhuatl. Como observado, os únicos textos que puderam ser conectados a um indivíduo específico foram os do Anotador 1, atribuídos ao frade dominicano Pedro de los Ríos.

Os interesses de cada um desses comentadores do Telleriano variam de acordo com a seção em que trabalhavam, porém também são moldados pelo tipo de informações de que dispunham, ou de que não dispunham, pois algumas vezes mostram um grande desconhecimento do assunto sobre o qual estão escrevendo. Isso pode ocorrer porque a tentativa de compreensão era sempre feita a partir de seus próprios termos ou de acordo com relatos de indígenas não versados nos assuntos sobre os quais estavam tentando aprender. É por isso que, muitas vezes, em comparação com o que foi fornecido sobre o mesmo assunto nos livros de Sahagún ${ }^{23}$ - o qual realizou um trabalho de compilação extremamente detalhista com a ajuda de membros instruídos da elite indígena -, parece que os anotadores do Telleriano Remensis não conseguiram reunir muitas informações. No geral, os frades que anotaram o Telleriano preenchem essa falta de dados com outros elementos, relativos a acontecimentos do período colonial, por exemplo, ou às

22Esse indivíduo foi denominado Anotador 2 devido à ordem de aparição dos textos. Ainda que tenha sido o primário da seção do Xiuhpohualli, são os textos do Anotador 1, Pedro de los Ríos, que aparecem primeiro no códice, no canto superior esquerdo da primeira página. A opção de designar Ríos como o Anotador 1 também se deve à sua importância, pois, além de ter sido o único indivíduo identificado, é também o único que incluiu anotações em todas as seções do códice e, possivelmente, foi o compilador do manuscrito.

${ }^{23}$ Bernardino de Sahagún, Historia general de las cosas de Nueva España, 10. ed., México, Editorial Porrúa, 1999, p. 17. 
suas próprias experiências, as quais tinham apenas uma pequena relação com o assunto ou com a data ou período sobre o qual escreviam. Quiñones Keber ${ }^{24}$ afirma que existe uma tendência desses anotadores em ultrapassar a descrição dos rituais para contar incidentes de interesse histórico e etnográfico.

O Anotador 2, por exemplo, que escreveu textos extensos no Xiuhpohualli e Tonalpohualli e demonstrou ser um religioso - possivelmente dominicano, devido a seu conhecimento dos locais onde havia unidades dessa ordem -, explicou que a festa do "mês" vey tecuilvitl ${ }^{25}$ foi aquela que os indígenas estavam realizando quando ocorreu a matança que desencadeou o episódio da Noche Triste em México Tenochtitlan. Já no seguinte "mês", mic caylhuitl, ao falar sobre a festa dos mortos, quando colocavam comidas e bebidas nas sepulturas, o mesmo acabou descrevendo os costumes relativos ao modo de enterrar os mortos dos mixtecas e zapotecas. Em outras partes, conecta o "mês" com o período em que Cortés terminou de subjugar México Tenochtitlan, ou com sua entrada pela primeira vez no Vale do México. Enfim, relacionou eventos ocorridos durante o período colonial aos "meses" ou às festas do Xiuhpohualli, sem, muitas vezes, acrescentar dados significativos sobre as próprias festas.

Isso não acontece somente com o Anotador 2. Pedro de los Ríos, o Anotador 1, que parece ter trabalhado em conjunto com o 2 nas seções do Xiuhpohualli e do Tonalpohualli, também descreveu muitos elementos de suas experiências pessoais ou acontecimentos relacionados aos espanhóis em diferentes áreas da Nova Espanha. Por exemplo, completou a descrição fornecida pelo Anotador 2 quando este escrevia sobre o modo dos mixtecas e zapotecas enterrarem os mortos, adicionando o dos mexicas, que, segundo ele, foi herdado dos otomis. Já no "mês" de ochpaniztli, mencionou que foi nesse período que Cortés pisou em terra pela primeira vez (ou seja, pisou no território que viria a ser a Nova Espanha); e relatou também, no Tonalpohualli, página 15r, que viu as coroas representadas nas pictografias dos deuses Tonacateotl e Mictlantecuhtli nos capitães da guerra de Coatlan.

Em nossa opinião, essa "tendência", utilizando o termo empregado por Quiñones Keber, dos anotadores do Telleriano para contar incidentes históricos ou etnográficos pode ser explicada pela falta de conhecimentos mais profundos dos frades sobre os assuntos representados nas pictografias e/ou também por informações limitadas, caso estivessem usando informantes indígenas.

Por outro lado, os Anotadores 1 e 2 não demonstraram total desconhecimento sobre os deuses e as festividades. Algumas vezes, fizeram alusão aos deuses e a suas atribuições, cerimônias do Xiuhpohualli e eventos relacionados aos dias ou períodos do Tonalpohualli. Sobre esses assuntos, Quiñones Keber ${ }^{26}$ acredita que eles mostrem mais interesse pelos deuses do que pelos rituais. A autora afirma que especialmente Ríos dá grande importância às deidades

\footnotetext{
${ }^{24}$ Eloise Quiñones Keber, Codex Telleriano-Remensis: ritual, divination and history in a pictorial Aztec manuscript, Austin, University of Texas Press, 1995, p. 138.

${ }^{25}$ Para as palavras em náhuatl empregadas nos textos, serão utilizadas as grafias do próprio códice.

${ }^{26}$ Eloise Quiñones Keber, op cit., p. 147-148.
} 
honradas, sua aparência visual e papéis que desempenham na religião e nos rituais indígenas e nas histórias mitológicas.

O conhecimento de Pedro de los Ríos parece ser limitado, mas escreve sobre práticas realizadas pelo povo durante algumas festas, como a chamada grande festa dos mortos, em vey mic caylhuitl, quando subiam nos terraços de suas casas para fazer "orações" aos mortos da família. Apresenta também conhecimento de mitos indígenas sobre os deuses, como quando se refere a Tezcatlipoca como aquele que enganou Quetzalcoatl, uma alusão a uma parte da história de Topiltzin Quetzalcoatl de Tula. Além disso, conhece alguns atributos dos deuses, como o pé faltante de Tezcatlipoca. Também diz que, no dia 6 cana ${ }^{27}$ os indígenas faziam uma grande festa a Quetzalcoatl em Cholula e que Huehuecoyotl era o deus dos otomis.

Quanto ao Anotador 2, este também demonstrou alguns conhecimentos sobre os ritos e costumes religiosos, como quando explicou a razão de os indígenas deixarem oferendas para os mortos em mic caylhuitl (segundo ele, para que pudessem suportar a difícil jornada ao lugar de descanso das almas, no último nível do Mictlan), ${ }^{28}$ ou quando falou que varriam as casas e os caminhos em ochpaniztli, ou, ainda, que faziam sacrifícios gladiatórios de guerreiros em panquetzaliztli, entre outros. No caso dos textos do mesmo autor no Tonalpohualli, devido ao caráter adivinhatório dessa seção, estão mais relacionados ao agouro a que era submetido um indivíduo que nascia na Trecena ou num dia determinado dentro da Trecena sobre a qual se refere. Portanto, seu foco recai sobre os prognósticos dos dias do Tonalpohualli.

Sobre essas informações a respeito dos rituais e prognósticos, é interessante ressaltar que temos a impressão de que eram de conhecimento geral do povo, pois tanto o Anotador 2 como os outros comentadores se referem, no caso do Tonalpohualli, a aspectos simples das previsões, com os quais as pessoas comuns deviam ter familiaridade, uma vez que costumavam consultar frequentemente os adivinhos ou tonalpouhque, especialmente quando as crianças nasciam - para que suas sortes fossem lidas. Além disso, alguns outros eventos ligados ao Tonalpohualli ou descritos no Xiuhpohualli pelos anotadores deviam ser do conhecimento de todos ou de uma parcela significativa da população, como quando mencionam o dia em que eram julgados os "adúlteros" e ladrões, ou o dia de mau agouro para os mercadores, quando corriam risco de perder suas mercadorias caso empreendessem jornadas de comércio, ou, ainda, aqueles dias em que todos deviam ficar em casa por serem muito perigosos, como quando baixavam à terra as mulheres mortas no parto, as Cihuateteo, que tinham aparência monstruosa. Certamente, esse tipo de evento, ligado ao temor das populações ou a importantes restrições, devia ser bem conhecido pela população. Não acreditamos que os anotadores tenham tido acesso a informações detalhadas, como aquelas que poderiam ter sido

${ }^{27}$ Um dos dias do calendário mesoamericano.

${ }^{28} \mathrm{Na}$ língua náhuatl, Mictlán se refere ao inframundo das culturas indígenas mesoamericanas, para onde a maioria dos seres humanos se dirigia após sua morte. 
fornecidas por um tonalpouhque, por exemplo, o qual devia conhecer os prognósticos relacionados a todos os dias do calendário, pois esse era seu trabalho. $\mathrm{O}$ fato de o Anotador 2 só mencionar os prognósticos de alguns poucos dias é um indício de que teve acesso a limitadas informações, possivelmente as que ficavam mais marcadas na memória das populações.

No "mês" ochpaniztli os indígenas celebravam a
festa "daquela que peco por comer la fruta del arbol",
associação direta como "pecado original" cristão

Isso não ocorre somente em relação aos prognósticos do Tonalpohualli, mas também nas descrições das festas do Xiuhpohualli. No geral, as informações oferecidas pelos anotadores principais dessa seção (Anotadores 1 e 2) mostram aspectos mais populares das festas. Sobre tal assunto, Quiñones Keber $^{29}$ menciona que os autores preferem explicar como as festas eram observadas pelas populações em geral. Porém, para nós, nesse caso, não devia tratar-se de uma "preferência" dos anotadores, mas de uma consequência do tipo de informações às quais tinham acesso. Possivelmente, seus informantes não deviam ser especialistas nos assuntos sobre os quais os frades estavam escrevendo e, por isso, mesmo que fossem da elite indígena, tinham as mesmas impressões e conhecimentos que as pessoas comuns.

Outros tipos de descrição contidos nas duas primeiras seções do códice se referem à interpretação de elementos específicos representados nas pictografias - como os atributos dos deuses - ou à tradução do significado do nome dos deuses representados. Com referência ao segundo aspecto, os Anotadores 1 e 2 revelam com frequência o significado dos nomes dos "meses" do Xiuhpohualli. Já no Tonalpohualli, essa tarefa de tradução fica principalmente a cargo do Anotador 1, Pedro de los Ríos, e do 3, o glosador primário dessa segunda seção do códice.

Ainda para Quiñones Keber, ${ }^{30}$ o indivíduo que realizou as anotações primárias do Tonalpohualli, ou seja, para nós, o Anotador 3, aparenta ser um indígena. No entanto, essa conclusão se deve ao fato de a autora acreditar que o comentarista dos textos primários do Tonalpohualli seja também aquele que realizou as palavras e os textos em letra gótica do códice, a maioria em náhuatl. A autora supõe que somente um indígena poderia ter escrito as palavras em náhuatl, com o que não estamos de acordo. Essas poderiam ter sido realizadas

${ }^{29}$ Eloise Quiñones Keber, Codex Telleriano-Remensis: ritual, divination and history in a pictorial Aztec manuscript, Austin, University of Texas Press, 1995, p. 138.

30/dem, Ibidem, p. 161 
por um missionário que conhecesse bem o idioma ou que estivesse fazendo uma transliteração a partir do som dessas palavras, proferidas por um indígena ou um mestiço, uma vez que a maioria delas se refere a nomes de deuses, festas e dias calendáricos utilizados antes da conquista. Dos cinco indivíduos que escreveram palavras em náhuatl no códice, podemos afirmar que pelo menos dois deles são religiosos, devido ao conteúdo do restante de seus comentários que, por serem mais extensos, possuem diversos dados disponíveis para análise.

Portanto, levando-se em consideração somente os textos atribuídos ao Anotador 3, os primários da segunda seção e os primários do início dos Anais Históricos, veremos que é difícil sustentar a hipótese de que seja um indígena se nos baseamos na premissa de Quiñones Keber, uma vez que ele não foi o autor das palavras em náhuatl. Além disso, há diversos indícios em seu texto que nos levam a acreditar que seja um frade, possivelmente da mesma Ordem que Pedro de los Ríos. Talvez ele não fosse tão experiente como os Anotadores 1 e 2, os quais demonstram experiência em diversos locais da Nova Espanha onde havia unidades da Ordem Dominicana, mas isso não significa que não possa ser um frade. Seus comentários o colocam mais próximo dos missionários, pois, além de alguns outros pequenos detalhes, refere-se aos costumes indígenas em terceira pessoa do plural, enquanto se identifica com os espanhóis na primeira.

Na maior parte da segunda seção do códice, o Anotador 3 oferece algumas informações sobre as realizações e atribuições dos deuses, mas, nas últimas Trecenas, se restringe à identificação do deus patrono. Parece mais provável que tenha obtido esses dados de algum ou alguns informantes indígenas. Mas, além dos comentários sobre os deuses patronos no Tonalpohualli, menciona repetidamente os jejuns, ou seja, quais os dias de cada Trecena em que os indígenas os realizavam. Em outra passagem, explica que Chalchiuhtlicue foi a deusa que "quedo del dilúvio". Esses últimos aspectos da religião indígena citados, que curiosamente possuem paralelo com os ritos e histórias cristãs, demonstram características compatíveis com os interesses dos missionários.

No entanto, as partes dos textos do Anotador 3 que podemos conectar a aspectos do cristianismo são muito menores do que aquelas encontradas nos comentários de seus companheiros, Anotadores 1 e 2, em que essas referências são abundantes. Por exemplo, no Xiuhpohualli, Ríos relaciona a "festa de todos os deuses", em vey pachtli, à "festa de todos os santos" católica e, quando escreve sobre a festa panquetzaliztli, o Anotador 2 descreve a realização de uma cerimônia que associa com a comunhão.

\section{A cosmovisão cristã no Telleriano Remensis}

Em geral, ao observarmos os textos dos anotadores principais da primeira seção do códice, é possível notar que, quando abordam as cerimônias realizadas durante as festas, eles fazem, com frequência, analogias a práticas cristãs. Ríos afirma que, no "mês" ochpaniztli, na página 3r, os indígenas celebravam 
a festa "daquela que peco por comer la fruta del arbol", associação direta com o "pecado original" cristão. Nessa mesma página, o autor refere-se a Xochiquetzal como a primeira deusa que pecou. Escreve também sobre anjos da guarda e diz que em atemoztli celebravam a festa do abaixamento das águas do dilúvio. Já na segunda seção, do Xiuhpohualli, o mesmo associa a figura feminina da página 11r (a qual nomeia Ysnextli e depois Suchiqueçal) a Eva, dizendo que sempre a pintam chorando e olhando para seu marido, Adão, identificado como Huehuecoyotl. Também é mencionado que o deus representado na página $16 \mathrm{v}$ foi um dos que pecaram no Paraíso; e, sobre uma figura da página 23r, afirma que é o diabo quando estava enganando Eva antes que pecasse. Além disso, refere-se aos deuses, muitas vezes, como diabos e afirma que foi por terem se atrevido a fazer sacrifícios que vieram as destruições do mundo.

O Anotador 2, por sua vez, também escreve sobre jejum, pecado e fim do mundo. Na página 13r (Tonalpohualli), em que foi representada a imagem de uma árvore quebrada, ele faz um comentário bastante interessante:

\section{[...] tamoancha e xuchitlyvcacan es el lugar donde fueron criados los dioses que ellos tenian que casi es tanto como dezir el parayso terrenal y asi dizen que estando estos dioses en aquel lugar se des- mandavan em cortar rosas y ramas de los arboles y que por esto se enojo mucho el Tonaceteuctli y la mujer Tonacaciuatl y que los echo dalla de aquel lugar y asy vinieron unos a la tierra y otros al ynfierno y estos son los que a ellos ponen los temores. ${ }^{31}$}

Assim, nota-se frequentemente a referência a mitos, cerimônias e costumes indígenas que tenham paralelo com aspectos da cultura ocidental cristã. Os anotadores parecem enfatizar elementos com os quais tinham familiaridade, buscando a si mesmos no outro. Para traduzir a cultura do outro, utilizam comparações com elementos de sua própria cultura. ${ }^{32}$ Sendo frades cristãos, acabam explicando a religião indígena usando como referência elementos que fazem parte das narrativas bíblicas e práticas e liturgias da Igreja Católica. Para Cristina Pompa, “[...] o que os missionários, os cronistas, os agentes do governo colonial apresentam em suas fontes é sua própria imagem deformada no espelho, em virtude do processo de tradução [...]".33

Quiñones Keber ${ }^{34}$ também observou a relação das histórias e práticas cristãs com as indígenas nos textos do Telleriano Remensis, acreditando que se tratam de analogias realizadas para que personagens e eventos indígenas sejam mais acessíveis ao público espanhol. Porém, dentre tantas histórias, por qual razão os frades escolheram exatamente as desse tipo para relatarem? Será que se trata somente da apreensão de elementos que podiam compreender? Em

\footnotetext{
${ }^{31}$ Eloise Quiñones Keber, Codex Telleriano-Remensis: ritual, divination and history in a pictorial Aztec manuscript, Austin, University of Texas Press, 1995, p. 29.

${ }^{32}$ François Hartog, O espelho de Heródoto. Ensaio sobre a representação do outro, Belo Horizonte, Editora da Universidade Federal de Minas Gerais, 1999, p. 224-245

${ }^{33}$ Cristina Pompa, Religião como tradução: missionários, Tupi e Tapuia no Brasil colonial, Bauru, Editora da Universidade do Sagrado Coração, 2003, p. 27.

${ }^{34}$ Eloise Quiñones Keber, op cit., p. 146.
} 
nossa opinião, não se trata de coincidência ou somente do uso de analogias para tornar o texto compreensível; parece, na verdade, uma escolha mais profunda, um direcionamento do olhar, tendo em mente algumas preocupações.

A menção ao dilúvio é a mais frequente entre os anotadores, principalmente no caso de Pedro de los Ríos. Ele chega a destacar em toda a seção do Tonalpohualli quais são os deuses que sobreviveram ao dilúvio. Ríos possui quase uma obsessão sobre a relação do dilúvio com os deuses e as outras histórias do universo mitológico-religioso indígena. Para ele, esse evento parece ser um marco. Por exemplo, os sacrifícios e os auto-sacrifícios começaram a ser feitos depois do dilúvio e a estrela Vênus foi criada antes dele.

Sobre essa questão do dilúvio, Quiñones Keber afirma que

while one might be tempted to see these as Christian allusions, they may actually refer to the floods that destroyed the last of the four previous worlds (or 'suns'), presided over by the water goddess Chalchiuhtlicue $[\ldots]^{35}$

Desse modo, a autora menciona que as anotações de Pedro de los Ríos com relação ao dilúvio não se relacionam ao dilúvio bíblico cristão, mas ao fim de uma das eras cosmogônicas encontradas em um dos mitos astecas, conhecido como a "Lenda dos Sóis" ${ }^{36}$ Esse mito discorre sobre a existência de quatro eras anteriores que acabaram em desastres naturais, sendo a representação mais conhecida delas encontrada na chamada Pedra do Sol, em que foram entalhados os símbolos calendáricos referentes aos dias em que ocorreram tais desastres apocalípticos nas quatro eras anteriores à atual:

4 jaguar: quando o mundo era povoado por gigantes, os quais foram devorados por jaguares;

4 vento: quando o mundo foi destruído por ventos e furacões;

4 chuva: quando o mundo foi destruído por chuvas de fogo; $\mathrm{e}$

4 água: quando o mundo foi destruído por um dilúvio, causado por águas enviadas pela deusa Chalchiuhtlicue. ${ }^{37}$

Englobando essas quatro representações, na Pedra do Sol, em maior dimensão, encontra-se também a da era atual, que é a de 4 movimento, na qual o mundo encontrará seu fim em terremotos. O misticismo apocalíptico, comum entre os religiosos, especialmente entre os franciscanos, devia fazer com que mitos indígenas relacionados a fins apocalípticos, como é o caso da "Lenda dos Sóis", chamassem bastante atenção. Segundo Boxer, ${ }^{38}$ em local algum esse fervor apocalíptico foi mais demonstrado do que na Nova Espanha.

Portanto, não nos parece coincidência que, dentre quatro diferentes fins da "Lenda dos Sóis", foi justamente aquele referente ao ocasionado por um dilúvio

${ }^{35}$ Eloise Quiñones Keber, Codex Telleriano-Remensis: ritual, divination and history in a pictorial Aztec manuscript, Austin, University of Texas Press, 1995, p. 149.

${ }^{36}$ Primo Feliciano Velázques (Ed.), "Leyenda de los Soles", Códice Chimalpopoca: Anales de Cuauhtitlán y Leyenda de los Soles, México, Universidad Nacional Autónoma de México, 1945, p. 119-123.

${ }^{37}$ Ether Pasztory, Aztec Art, New York, Abrams, 1983, p. 170.

${ }^{38}$ Charles R. Boxer, A igreja e a expansão ibérica (1440-1770), Lisboa, Edições 70, 1989, p. 138. 
que tenha chamado mais a atenção dos frades dominicanos, anotadores do Códice Telleriano Remensis. A coincidência entre o dilúvio descrito nas Sagradas Escrituras e lendas indígenas sobre um fim apocalíptico causado pela água chamou a atenção de diversos religiosos que atuaram ou escreveram sobre a América. Na "Historia General" de Fernández de Oviedo, por exemplo, foi publicada uma "Informação do Provincial Mercedário Francisco de Bobadilla sobre as crenças, ritos e cerimônias dos índios Nicarágua ao Governador Pedrarias Dávila". ${ }^{39}$ Trata-se de uma lista de questionamentos feitos pelo Frei Francisco de Bobadilla a alguns "caciques" indígenas a respeito de suas crenças e costumes - alusivos à cosmogonia indígena, aos ritos, deuses, entre outros. Eis aqui uma parte do interrogatório e suas respostas, nas quais "F." se refere ao frade e "I.", aos indígenas:

F. Sabes ou ouvistes dizer se, depois que o mundo foi feito, perdeu-se ou não? I. Ouvi meus pais dizerem que fazia muito tempo que o mundo se tinha perdido pela água, e que aquilo já era passado.

F. Sabes se afogaram-se todos os homens?

I. Não sei, mas os teotes reedificaram o mundo com mais gente, aves e todas as coisas.

F. Como os teotes escaparam? Foi em algum lugar alto, numa canoa ou barca?

I. Só sei que eles são deuses, como se afogariam?40

Por esse fragmento das questões, pode-se notar que o referido Mercedário buscava respostas específicas sobre alguns assuntos. Em nossa opinião, o principal interesse dos missionários por assuntos particulares da cultura indígena devia-se a uma busca por determinadas informações que pudessem ajudá-los a encaixar esses povos americanos em suas próprias crenças, ou seja, ao conteúdo das Sagradas Escrituras, especialmente ao Gênesis. Para Simaan e Fontaine, o Novo Mundo e outras descobertas:

[...] colocavam problemas embaraçosos para a Igreja, na medida em que ficava difícil conciliá-las com as Escrituras. Que povos eram então aqueles, que não conheceram o dilúvio, nem a Redenção? Teriam cometido o pecado original? Que lugar atribuir-lhes na Criação? E todos aqueles animais desconhecidos, será que tinham lugar na Arca de Noé? Que crédito deveria ser dado ao relato do Gênesis? ${ }^{41}$

Em diversas crônicas coloniais escritas por religiosos, podem ser encontradas explicações alternativas para a existência dos nativos americanos, pois a descoberta do Novo Mundo suscitou discussões a respeito do lugar que os indígenas ocupariam nas Sagradas Escrituras e se já haviam recebido "a verdadeira fé".

${ }^{39}$ Paulo Suess, A conquista espiritual da América Espanhola. 200 documentos - século XVI, Petrópolis, Vozes, 1992, p. 127

40/dem, Ibidem

${ }^{41}$ Arkan Simaan; Joële Fontaine, A imagem do mundo. Dos babilônios a Newton, São Paulo, Companhia das Letras, 2003, p. 117. 
Com o Novo Mundo descobre-se também uma nova humanidade. Resta o problema crucial de inseri-la na economia divina, o que implica incluí-la na genealogia dos povos. Para isso, não há outra solução senão a da continuidade, senão abrir-lhes um espaço na cosmologia europeia. Por que a humanidade é uma só, os habitantes do Novo Mundo descendem necessariamente de Adão e Eva, e portanto de um dos filhos de Noé, provavelmente do maldito, Cam, aquele que desnudou seu pai $[\ldots]^{42}$

Assim, para os cristãos daquele tempo, o dilúvio foi um evento universal, tendo sobrevivido somente Noé e sua família. Os povos da Europa, Ásia e África eram descendentes dos filhos de Noé, mas e os homens da América? Caso fossem descendentes de um dos filhos de Noé, como chegaram ao continente americano, tão distante da Europa? Por conta da busca por essas explicações, Acosta ${ }^{43}$ foi o primeiro a propor uma migração ao continente americano por terra, pelo Norte, antecipando as teorias sobre o povoamento da América pelo Estreito de Bering.

Partindo de tais problemas, era natural que os religiosos buscassem eventos ou mitos das culturas indígenas que pudessem explicar a existência desses grupos no contexto das narrativas bíblicas. O que estava em jogo era a credibilidade de um texto que, naquele tempo, era aceito como uma história verdadeira, a qual suportava toda a concepção de mundo cristão. Por isso, não concebemos as referências a um dilúvio no Códice Telleriano Remensis somente como alusões às histórias indígenas, mas também como resultado das preocupações dos anotadores. Nesse aspecto, o conteúdo das anotações do códice está relacionado a uma série de outros textos produzidos por religiosos durante o período colonial, pois, quer estivessem explicando as pictografias ou escrevendo livros, esses indivíduos tinham interesses e preocupações em comum. ${ }^{44}$

Ronaldo Vainfas ${ }^{45}$ lembra que "[...] a 'descoberta' do Novo Mundo foi na realidade um processo de natureza dupla, pois o desvelamento da alteridade ameríndia parece ter implicado a (re)construção da identidade cristã ocidental". Assim, em virtude dos problemas que a existência dos americanos desencadeou para a ideologia cristã, alguns de seus dogmas tiveram que ser discutidos e reafirmados.

\section{Os anotadores do Telleriano Remensis e a evangelização indígena}

O domínio das línguas nativas e a proximidade diária com as comunidades deviam dar aos missionários acesso a inúmeras informações sobre similaridades

\footnotetext{
42Manuela Carneiro da Cunha, "Imagens de Índios do Brasil: o século XVI", Estudos Avançados, vol. 4, n. 10, São Paulo, 1990, p. 102.

43.Joseph Acosta, Historia natural y moral de las Indias, México, Fondo de Cultura Económica, 2006, p. 60-63. ${ }^{44}$ Alvim apontou a presença de tal cosmovisão europeia em algumas crônicas missionárias do século XVI em: Márcia H. Alvim, Dos céus e da terra: astrologia judiciária e descrição da superfície terrestre nos relatos missionários da Nova Espanha do Século XVI, Tese de Doutorado em Ciências, Universidade Estadual de Campinas, Campinas, 2007, p. 99-141.

${ }^{45}$ Ronaldo Vainfas, $A$ heresia dos índios. Catolicismo e rebeldia no Brasil colonial, São Paulo, Companhia das Letras, 1995, p. 23.
} 
entre o universo religioso indígena e o cristão. É, portanto, compreensível que os textos do Telleriano Remensis apresentem essas analogias, assim como neles aparecem comparações entre práticas de diferentes tradições culturais indígenas, uma vez que pelo menos dois anotadores, um deles Pedro de los Ríos, mostram experiência em distintas regiões da Nova Espanha.

Segundo Santos - que analisou crônicas missionárias, como as de Sahagún, Durán e Acosta, além de códices e textos nativos - , ao longo do século XVI, os relatos nahuas sobre o passado sofreram uma transformação, denominada de "fabulização", devido à intervenção dos missionários cristãos:

[...] podemos perceber que o objetivo central desses missionários em suas Historias não era recolher ou transcrever as explicações nativas sobre o passado para preservá-las. Ao contrário, o objetivo declarado era demonstrar a falsidade de tais relatos diante da versão bíblica da criação do mundo e dos primeiros tempos do que supunham ser a história humana. ${ }^{46}$

A complexidade das relações entre indígenas e missionários no início do período colonial demonstra que a manipulação e adequação das histórias de ambos os grupos foi uma constante nesse processo de interação entre as culturas. Os missionários desqualificavam as histórias indígenas, tirando-lhes o crédito de "verdade" e as anunciando como histórias imaginárias, ${ }^{47}$ ao mesmo tempo em que tentavam conhecer com maior profundidade as práticas religiosas nativas para que pudessem detectar manifestações idolátricas. Por outro lado, buscavam nas tradições indígenas elementos que se associassem com as histórias cristãs, a fim de que pudessem inserir esses povos na história humana relatada na Bíblia - como é o caso do dilúvio, uma vez que também existiam lendas sobre dilúvios em várias culturas indígenas. Além disso, podiam também estar tentando criar e/ou manter vínculos entre o passado indígena e o presente colonial, para que as ideias cristãs fossem mais facilmente aceitas e incorporadas e para que fizessem sentido dentro do universo cultural nativo.

Segundo Ricard, ${ }^{48}$ uma das modalidades de conversão partia das similaridades entre elementos indígenas e cristãos; por exemplo, Schwaller explica que havia entre os astecas uma forma de confissão, chamada neyolmelahualiztli, mas:

[...] el concepto de pecado no existía entre los aztecas; de ahi que los frailes tuvieran que poner en relación el concepto cristiano de pecado con el concepto indio de impureza o suciedad. Pudieron así éstos utilizar el ritual azteca de la confesión como punto de partida. ${ }^{49}$

Portanto, é possível que os missionários também buscassem ou enfocassem elementos do passado indígena que pudessem ajudá-los na tarefa de

\footnotetext{
${ }^{46}$ Eduardo Natalino dos Santos, Calendário, cosmografia e cosmogonia nos códices e textos nahuas do século XVI, Tese de Doutorado em História, Universidade de São Paulo, São Paulo, 2005, p. 398.

${ }^{47}$ Idem, Ibidem, p. 394-399.

${ }^{48}$ Robert Ricard, La conquista espiritual de México, México, Fondo de Cultura Económica, 1986, p. 409-410.

${ }^{49} \mathrm{~J}$ ohn F. Schwaller, "La iglesia en la América Colonial española", Historia General de América Latina: consolidación del orden colonial, v. III2, Madrid, Unesco/Editorial Trotta, 2007, p. 544-545.
} 
evangelização, quer estivessem preocupados em tornar seus ensinamentos mais eficientes ou simplesmente tentando combater a idolatria. Nesse sentido, o Telleriano Remensis deve ter sido um importante recurso para os evangelizadores. Pelo grau de deterioração visível no manuscrito original, é possível perceber que ele foi bastante utilizado ao longo dos séculos XVI e XVII. Suas seções foram manuseadas separadamente, pois muitos dos bifólios de seus cadernos se despregaram completamente, resultando na perda de muitos fólios de seus inícios e finais, antes mesmo de o documento ter chegado à Biblioteca Nacional de França, em 1700, onde se encontra até hoje. Seu estado ao chegar a essa biblioteca demonstra que não era um documento acabado. O códice foi encadernado somente quando já estava na Europa (possivelmente na Espanha), na segunda metade do século XVII, depois de ter perdido muitos de seus fólios.

O Telleriano Remensis devia ser uma fonte de consulta para se obterem informações sobre as tradições indígenas, uma vez que passou pelas mãos de diversos religiosos, os quais, além de o consultarem, incluíram novos detalhes que complementavam ou corrigiam o conhecimento nele expresso. Esse uso intenso dos conteúdos do códice deve ter se estendido por muitos anos após suas últimas anotações, para que sofresse os danos e as perdas que apresentava quando chegou à França. Desse modo, suas características físicas sugerem que ele pode ter sido utilizado como suporte para a formação de evangelizadores, a fim de que estes fossem capazes de identificar manifestações idolátricas e fiscalizar os indígenas. Logo, o Telleriano Remensis também pode ter sido um recurso contra a idolatria.

Todavia, atribuir somente aos europeus o papel de atores no contexto da evangelização seria olhar apenas uma das faces da história. A nova ideologia tinha que fazer sentido para os indígenas e, por isso, era necessária uma espécie de interconexão entre ambas as cosmovisões ou uma "tradução" da ideologia cristã nos termos indígenas, para utilizar o termo consagrado por Cristina Pompa, ${ }^{50}$ em que os povos nativos também seriam atores no processo. As histórias e práticas cristãs tiveram que ser incorporadas ao mundo preexistente, fazendo com que as concepções religiosas indígenas e, em menor grau, também as europeias, passassem por constantes processos de resignificação, ${ }^{51}$ pois as proibições de sacrifícios e outras práticas foram somente uma parte superficial das mudanças.

Era um processo multidirecional de absorção, adaptação e incorporação, mas sempre em desequilíbrio, devido à desigualdade de forças das tradições envolvidas e à capacidade da cultura hispânica de limitar, extirpar, censurar e reprimir, com os instrumentos do Estado e da Igreja, qualquer coisa que contestasse sua cosmografia..$^{2}$

${ }^{50}$ Cristina Pompa, Religião como tradução: missionários, Tupi e Tapuia no Brasil colonial, Bauru, Editora da Universidade do Sagrado Coração, 2003, p. 27.

${ }^{51}$ Resignificação no sentido proposto por Marshall Sahlins (Ilhas de História, Rio de Janeiro, Jorge Zahar Editores, 2003, p. 7, 15 e 190; e Historical metaphors and mythical realities. Structure in the early History of the Sandwich Islands Kingdom, Michigan, University of Michigan Press, 1985, p. 67).

52Stuart B. Schwartz, Cada um na sua lei. Tolerância religiosa e salvação no mundo atlântico ibérico, São Paulo, Companhia das Letras; Bauru, Editora da Universidade do Sagrado Coração, 2009, p. 261. 
As analogias, então, não deviam ser realizadas somente pelos missionários, mas também pelos indígenas, pois quando ouviam as histórias cristãs nas pregações ou leituras dos catecismos, ${ }^{53}$ deviam naturalmente fazer conexões com seus conhecimentos da antiga religião. Nesse âmbito, Manuela Carneiro da Cunha explica que havia, por parte dos indígenas, um “[...] esforço notável, simétrico ao dos missionários, de abranger o dessemelhante, de incorporar e tornar inteligíveis os estrangeiros e suas crenças". ${ }^{54} \mathrm{~A}$ busca por informações a respeito das culturas ameríndias por parte dos missionários, portanto, também deve tê-los ajudado a fazer com que as ideologias cristãs fossem compreendidas pelos nativos, mas estes seguramente as "traduziram" a partir de suas próprias concepções, da mesma forma que o conhecimento das tradições indígenas era construído pelos missionários a partir da cosmovisão europeia cristã.

Por isso, os conhecimentos compilados por esses religiosos, incluindo o conteúdo do Telleriano Remensis, devem hoje ser analisados com critério, pois, a despeito do esforço empreendido no sentido de conhecer os povos nativos, muitas vezes, esses europeus não foram muito além de sua própria cultura.

A compreensão que os anotadores do Códice Telleriano Remensis obtiveram do mundo nativo foi intermediada por seus próprios interesses e preocupações, como a extirpação da idolatria, a comprovação das narrativas das Sagradas Escrituras e a inserção dos indígenas na cosmogonia cristã. As frequentes menções ao dilúvio no Telleriano Remensis mostram claramente como os conhecimentos e ideologias dos nativos foram selecionados, manipulados e interpretados de acordo com as concepções ocidentais dos frades dominicanos que o compilaram. Assim, na tentativa de entender o outro, acabaram falando mais sobre si mesmos.

${ }^{53}$ Os frades desenvolveram inclusive catecismos pictográficos, conhecidos como "Códices Testerianos."

${ }^{54}$ Manuela Carneiro da Cunha, "Imagens de Índios do Brasil: o século XVI", Estudos Avançados, vol. 4, n. 10, São Paulo, 1990, p. 103. 